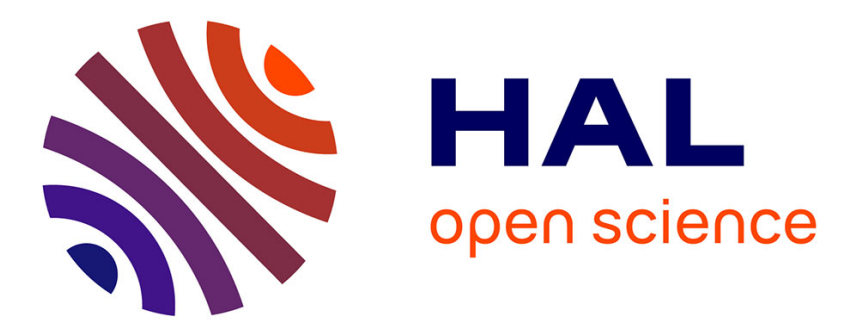

\title{
Development of an LC-MS-MS method for the quantification of taurine derivatives in marine invertebrates.
}

\author{
P. Chaimbault, Patrick Albéric, C. Elfakir, M. Lafosse
}

\section{To cite this version:}

P. Chaimbault, Patrick Albéric, C. Elfakir, M. Lafosse. Development of an LC-MS-MS method for the quantification of taurine derivatives in marine invertebrates.. Analytical Biochemistry, 2004, 332, pp.215-225. 10.1016/j.ab.2004.06.014 . hal-00067778

\section{HAL Id: hal-00067778}

\section{https://hal-insu.archives-ouvertes.fr/hal-00067778}

Submitted on 18 May 2006

HAL is a multi-disciplinary open access archive for the deposit and dissemination of scientific research documents, whether they are published or not. The documents may come from teaching and research institutions in France or abroad, or from public or private research centers.
L'archive ouverte pluridisciplinaire HAL, est destinée au dépôt et à la diffusion de documents scientifiques de niveau recherche, publiés ou non, émanant des établissements d'enseignement et de recherche français ou étrangers, des laboratoires publics ou privés. 


\title{
Development of an LC-MS-MS method for the quantification of taurine derivatives in marine invertebrates
}

\author{
P. Chaimbault ${ }^{\mathrm{a}}$, P. Alberic ${ }^{\mathrm{b}}$, C. Elfakir ${ }^{\mathrm{a}}$ and M. Lafosse ${ }^{\mathrm{a}}$ \\ 'Institut de Chimie Organique et Analytique, CNRS UMR 6005, Université d'Orléans, BP \\ 6759, F-45067 Orléans Cedex 2, France \\ ${ }^{b}$ Institut des Sciences de la Terre d'Orléans, CNRS UMR 6113, Université d'Orléans, BP \\ 6759, F-45067 Orléans Cedex 2, France
}

\begin{abstract}
Sulfur amino acids, such as taurine, hypotaurine, and thiotaurine, were found in high quantities in tissues of marine symbiotic organisms (e.g., bivalves, tubeworms) living close to hydrothermal vent sites. Therefore, they are assumed to play a key role in the S-oxidizing base metabolism or sulfide detoxification. We propose here a specific, rapid, and original analytical procedure for the direct determination of sulfur amino acids at the level of a few parts per billion in biological samples, avoiding the classical low specific post-column orthophthaldialdehyde derivatization step required by non-ultraviolet-absorbing molecules. Indeed, by coupling liquid chromatography on a porous graphitic stationary phase under isocratic conditions (10 mM ammonium acetate buffer adjusted to $\mathrm{pH} 9.3$ ) to tandem mass spectrometry (ionization process by pneumatically assisted electrospray in negative ion mode), it is possible to perform specific quantification of these metabolites in less than $10 \mathrm{~min}$ directly in biological matrices without any derivatization step or other tedious sample treatments. Thus, taurine, hypotaurine, and thiotaurine have been identified and assayed in several deep sea organisms, showing that the developed method is well suited for this kind of application.
\end{abstract}

Keywords: Underivatized amino acids; Liquid chromatography; Mass spectrometry; Taurine; Hypotaurine; Thiotaurine

Hydrothermal vents at mid-ocean ridges and hydrocarbon or brine seep areas are examples of special habitats based on chemolithotrophic or methyl-trophic primary production [1]. The high biomass densities in these ecosystems rely mainly on symbiotic associations between bacteria and unique invertebrates [2]. High amounts of unusual amino compounds have been found in the tissues of these symbiotic invertebrates, especially sulfur compounds [3], [4], [5] and [6]. Their metabolic role has been related to the S-oxidizing base metabolism [3], [4], [7] and [8], sulfide detoxification [9], and osmoregulation [10], [11] and [12]. These sulfur amino acids are compounds lacking in a chromophore group. Therefore, the majority of the chromatographic methods proposed for their characterization involve pre- or postderivatization to allow ultraviolet (UV) ${ }^{1}$ visible fluorometric detection [4], [5], [6], [7], [8], [9], [13], [14], [15], [16], [17], [18] and [19] or the use of the refractive index [10]. A few alternative methods involving another detection mode, such as electrochemical detection for hypotaurine [20] and taurine determination [21], have been proposed. Recently, nuclear magnetic resonance (NMR) ${ }^{[10]}$ and [22] and electrospray (ES) mass spectrometry (MS) ${ }^{[22] \text { and [23] }}$ were used to detect hypotaurine or taurine directly in tissue extracts, but none of these methods provides a reliable analytical method to characterize 
and quantify in a single run hypotaurine, taurine, and especially thiotaurine, specifically found in symbiotic deep sea invertebrates.

In general, because most of the employed detection methods are not specific, the liquid chromatography (LC) methods developed are long (40-60 min) so as to separate the sulfur amino acids from the non-sulfur-containing amino acids or other interfering compounds [4], [9], [10], [13], [16] and [17]. Thus, there is still a need for a simple (avoiding a derivation step) and rapid ( $\sim 10 \mathrm{~min}$ ) analytical method that is applicable to complex matrices and that is able to reliably characterize and quantify hypotaurine, taurine, and thiotaurine. Considerable progress has been made during the past 5 years or so concerning the chromatographic separation and detection of underivatized amino acids [24], [25], [26], [27], [28], [29], [30] and [31]. With the development of MS-MS methods, high sensitivity and selectivity can be achieved in the analysis of complex samples (e.g., biological matrices) [28], [29], [30] and [31], making it possible to determine trace amounts of amino acids without derivatization and total baseline chromatographic separation. This reduces the analysis time by eliminating laborious sample preparation and also reduces the errors introduced by the derivatization procedure. Several complementary chromatographic systems compatible with MS detection are now available for the separation of underivatized protein amino acids. They use ion pair reversed-phase LC on octadecyl silica [24], [26], [28], [29], 30] and [31] or porous graphitic carbon (PGC) [25] columns with volatile perfluorinated carboxylic acids (from trifluoroacetic acid to pentadecafluorooctanoic acid) as an ion pairing reagent. High selectivities have been obtained even for the most polar underivatized protein amino acids. Using this LC-MS-MS methodology, a successful quantification of glutamic acid, glutamine, and other relevant amino acids has been obtained

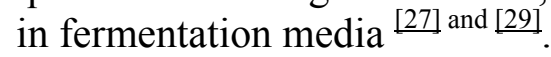

In this article, we describe an analytical method allowing the simultaneous determination of taurine, hypotaurine, and thiotaurine in tissues of some marine symbiotic invertebrates by LC-MS-MS. Two sulfur analogs, 2-aminoethylhydrogenosulfuric acid and 2aminoethylthiosulfuric acid, were evaluated as internal standards for quantification.

\section{Materials and methods \\ Reagents :}

Taurine $\left(\mathrm{NH}_{2}-\mathrm{CH}_{2}-\mathrm{CH}_{2}-\mathrm{SO}_{3} \mathrm{H}\right)$ and hypotaurine $\left(\mathrm{NH}_{2}-\mathrm{CH}_{2}-\mathrm{CH}_{2}-\mathrm{SO}_{2} \mathrm{H}\right)$ were purchased from Sigma, 2-aminoethyl hydrogenosulfuric acid $\left(\mathrm{NH}_{2}-\mathrm{CH}_{2}-\mathrm{CH}_{2}-\mathrm{O}-\mathrm{SO}_{3} \mathrm{H}\right)$ was purchased from Fluka, and 2-aminoethylthiosulfonic acid $\left(\mathrm{NH}_{2}-\mathrm{CH}_{2}-\mathrm{CH}_{2}-\mathrm{S}-\mathrm{SO}_{3} \mathrm{H}\right)$ was purchased from Aldrich. Pure crystalline thiotaurine $\left(\mathrm{NH}_{2}-\mathrm{CH}_{2}-\mathrm{CH}_{2}-\mathrm{SO}_{2} \mathrm{SH}\right)$ was prepared according to the method of Cavallini et al. [32], whereby a solution of hypotaurine in $0.2 \mathrm{~N} \mathrm{NaOH}$ is reacted with elemental sulfur in ethanol for $2 \mathrm{~h}$ at $85^{\circ} \mathrm{C}$. The solution is then placed at $-20{ }^{\circ} \mathrm{C}$ overnight. Washing of unreacted sulfur from the precipitate obtained was done with toluene in place of carbon disulfide. After dissolution in a minimal amount of water and filtration, thiotaurine was recrystallized in absolute ethanol at $-20{ }^{\circ} \mathrm{C}$ overnight.

High-performance liquid chromatography (HPLC)-grade methanol, ethanol, n-propanol, isopropanol, butanol, and pentanol were obtained from J. T. Baker (Noisy-le-Sec, France). Water was purified from an Elgastat UHQ II system (Elga, Anthony, France).

\section{Biological material :}

Three deep sea symbiotic bivalves (Calyptogena magnifica, Bathymodiolus thermophilus, and an undescribed vesicomyid clam from Barbados) and one tubeworm (Riftia pachyptila) were studied. Specimens of $R$. pachyptila were collected during a Hydronaut cruise (East Pacific Rise, $13^{\circ}(\mathrm{N})$. The tissues of the specimens of $C$. magnifica and B. thermophilus from Galapagos and the undescribed species from Barbados used during this investigation had

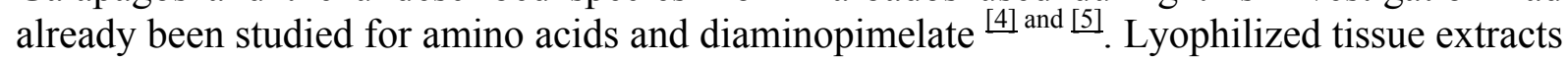


( $25-100 \mathrm{mg}$ ) were accurately weighed and extracted with cold $70 \%$ ethanol in accordance with [4]. Extracts were then filtered $(0.2 \mu \mathrm{m})$, evaporated, redissolved in $1 \mathrm{ml}$ water, and filtered again. Before injection onto the LC system, extracts were diluted by a factor of 10 with the LC mobile phase.

\section{Apparatus :}

LC-MS-MS was carried out on a PerkinElmer (Toronto, Canada) model LC-200 system binary pump (flow rate $200 \mu \mathrm{l} / \mathrm{min}$ ) and a PerkinElmer Sciex (Foster City, CA, USA) API 300 mass spectrometer triple quadrupole with ion spray as ion source. The mass spectrometer was operated in negative ion mode $(-4.0 \mathrm{kV})$. Injections were performed by a PerkinElmer series 200 autosampler fitted with a $10-\mu 1$ loop. A Harvard model 22 syringe pump was used to infuse the makeup solution in a sheath flow mode. Development of the LC method was performed using a Sedere (Vitry/Seine, France) Sedex 45 evaporative light scattering detector (ELSD), which was set with drift tube temperature at $45^{\circ} \mathrm{C}$ and nebulizer gas pressure at 2.2 bars, and a Shimadzu (Kyoto, Japan) CR-5A integrator.

Separation was carried out on a PGC column, Hypercarb-S $(100 \times 2.1 \mathrm{~mm}$ i.d., particle size $5 \mu \mathrm{m}$ ) from Hypersil (Runcorn, UK). The theoretical values of $\mathrm{pH}$ and ionic strength of buffers used as a mobile phase were calculated with PhoEBus, an application used for buffer studies (Analis, Namur, Belgium).

\section{Results and discussion}

Taurine-like compounds (Table 1) can be considered as amino acids. Thus, LC-MS-MS was investigated to replace the lengthy traditional LC-UV or fluorescence methods using pre- or postderivatization (mainly ortho-phthaldialdehyde) of the analytes. The first step in the development of the LC-MS or LC-MS-MS analytical methodology was the investigation of the most specific and sensitive conditions for detection (e.g., ionization mode, fragmentation).

\begin{tabular}{|c|c|c|c|}
\hline Name & Abbreviation & Formula & Nominal mass \\
\hline Hypotaurine (2-aminoethyl sulfinic acid) & $\mathrm{Hpt}$ & & 109 \\
\hline Taurine (2-aminoethyl sulfonic acid) & Tau & & 125 \\
\hline Thiotaurine (2-aminoethyl thiosulfonic acid) & Tht & & 141 \\
\hline 2-aminoethyl hydrogenosulfuric acid & 2-AEHS & & 141 \\
\hline 2-aminoethyl thiosulfuric acid & 2-AETS & & 157 \\
\hline
\end{tabular}

Table 1. : Names, abbreviations, formulas, and nominal mass (for MS) of studied sulfur amino acids

\section{Mass and tandem MS of taurine and its analogs :}

In MS, when electronebulization is used as an ion source, the choice between positive or negative detection ion mode is often made by taking into account functional groups on the molecular structure. Thus, to produce ions, basic functional groups were preferentially protonated (parent ion is $[\mathrm{M}+\mathrm{H}]^{+}$), whereas acidic groups were rather deprotonated (parent 
ion is $\left.[\mathrm{M}-\mathrm{H}]^{-}\right)$. Because of their zwitterionic nature, both ionization modes can be considered for amino acids.

For all of the sulfur amino acids studied, positive ion mode tandem MS leads mainly to a major fragment ion corresponding to a water loss. However, water loss is not specific enough for the assays in matrices because many protonated metabolites lose water during the fragmentation step.

In a negative ion mode, the MS-MS fragmentation is related to the anionic part of the sulfur amino acid, as displayed in Fig. 1. For example, the deprotonated molecular ion of taurine $\left([\mathrm{M}-\mathrm{H}]^{-}\right.$at $m / z$ 124) yields the $\left[\mathrm{SO}_{3}\right]^{-}$fragment at $m / z \quad 80$ (ion transition $124 \rightarrow 80$ ). For $2-$ AEHS $\left([\mathrm{M}-\mathrm{H}]^{-}\right.$at $\left.m / z 141\right)$, the observed fragment ion is $\left[\mathrm{HSO}_{4}\right]^{-}(\mathrm{m} / z$ 97) due to an additional proton shift mechanism occurring during the fragmentation step. For 2-AETS $\left([\mathrm{M}-\mathrm{H}]^{-}\right.$at $m / z$ 156), fragmentation occurs between the two sulfur atoms, yielding $\left[\mathrm{SO}_{3}\right]^{-}$ $(\mathrm{m} / \mathrm{z} 80)$ rather than $\left[\mathrm{S}_{2} \mathrm{O}_{3}\right]^{-}(\mathrm{m} / \mathrm{z} 112)$. For thiotaurine, the deprotonated molecular ion yields an $\mathrm{m} / z 96$ fragment corresponding to $\left[\mathrm{SO}_{2} \mathrm{~S}\right]^{-}$, confirming the structure (Table 1). Therefore, this kind of fragmentation leads to a more specific detection than a water loss. Moreover, Lillard et al. [22] found a significantly lower response in ES positive mode for taurine in collected biological samples than in ES negative mode. Moreover, the negative ion mode is even more interesting than the positive mode because it provides more specificity and also appears to give more sensitivity [22] for direct detection of the studied thioamines in biological samples. 

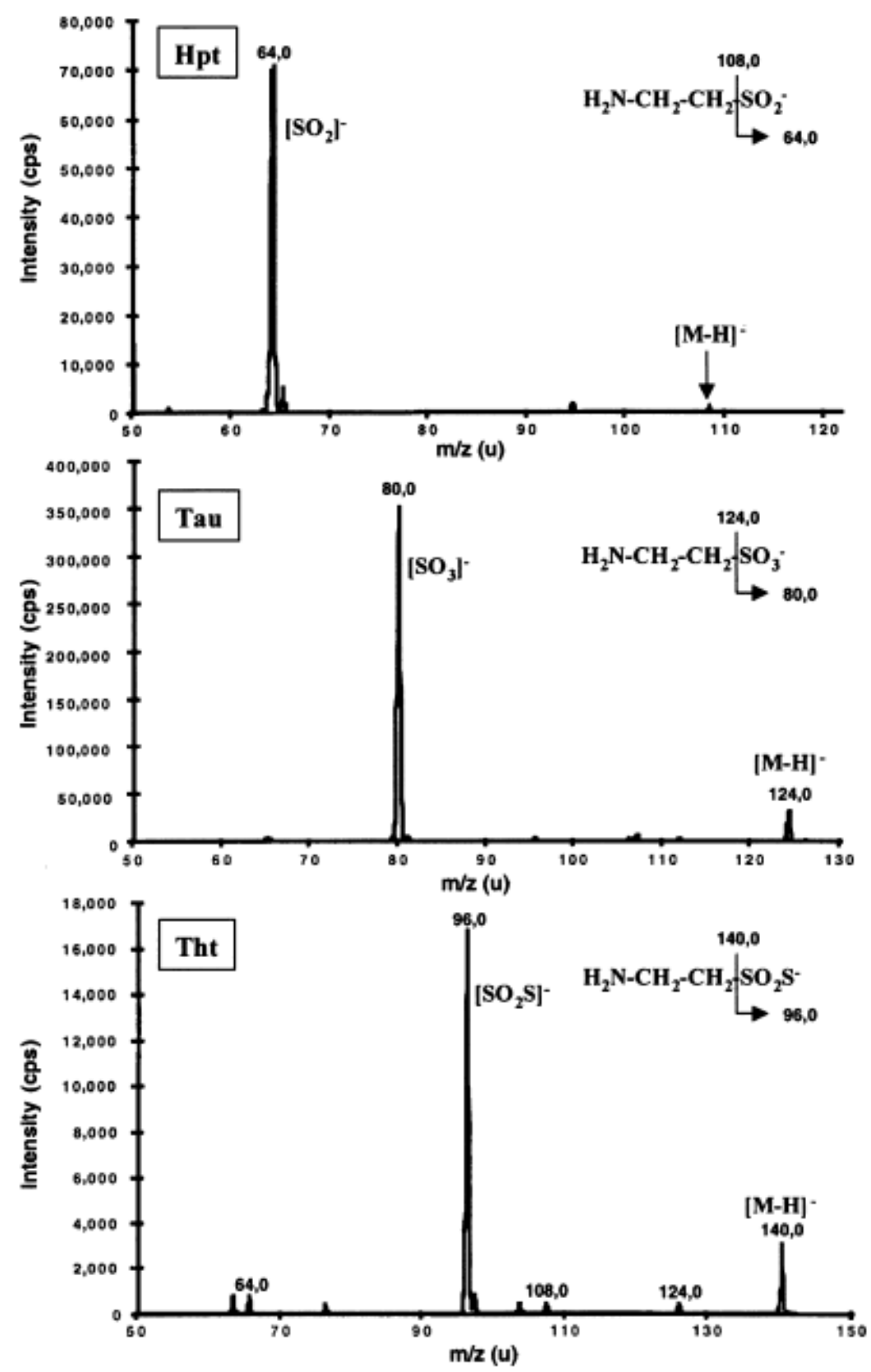

Fig. 1. Fragmentation (tandem MS) of hypotaurine, taurine, and thiotaurine in negative ionization mode at $25 \mathrm{eV}$ (collision energy). Ion spray voltage, $-4.0 \mathrm{kV}$. Hpt, Tau, and Tht were infused at $5 \mu \mathrm{l} / \mathrm{min}$ in the chromatographic mobile phase $(100 \mathrm{mg} / \mathrm{L})$.

Collision energy was then optimized to obtain the more sensitive MS-MS detection. The optimal levels of collision energy are $26 \mathrm{eV}$ for hypotaurine, $30 \mathrm{eV}$ for thiotaurine, and $32 \mathrm{eV}$ for taurine. Thus, these parameters were chosen and used in the subsequent studies.

For all of these reasons, the development of efficient sample preparation and LC conditions compatible with MS detection using a negative ion mode appeared to be satisfactory to quantify sulfur amino acids in biological samples. 


\section{Development of the LC method using a PGC stationary phase :}

As depicted in Fig. 1, the molecular weights of the molecules of interest are different. In addition, their fragmentation leads to the production of ions with different $\mathrm{m} / \mathrm{z}$ ratios, showing that mass, and in particular tandem MS, is sufficient to distinguish them specifically without any separation system. However, it is well established that matrices could induce an ion suppression effect due to potential interfering compounds, reducing the sensitivity and accuracy of detection. Moreover, some interfering molecules may exhibit the same ion transitions (e.g., isomers, isobars) as the studied solutes, leading to possible confusion. Thus, it is generally necessary to develop a separation method for two main reasons: (i) to exclude solutes of interest from the void volume where ion suppression is maximal given that most of the matrix compounds are eluted in this area and (ii) to maintain selectivity among the solutes of interest and other interfering solutes of the matrices when mass, or even tandem MS, detection is not specific enough.

Several suitable and complementary chromatographic systems compatible with MS detection are now available for the separation of underivatized proteinogenic amino acids [24], [25], [26], [27] and [28]. By using perfluorinated carboxylic acids as an ion-pairing reagent in the mobile phase, high amino acid selectivities can be obtained on the C8, C18 silica ${ }^{[24],[26] \text { and }[28]}$, or PGC ${ }^{[25]}$ and [27] stationary phases.

However, in the reversed-phase ion pairing chromatography (RP-IPC) system mentioned above for underivatized amino acids, the mobile phase is more suitable for the positive ion mode detection, particularly because the positive ion mode prevents the spectrometer from being contaminated by the negatively charged ion pairing agent [24]. Using the negative ion mode, in contrast, the ion pairing agent can fully and easily enter the spectrometer and contaminate it. Consequently, these RP-IPC systems using perfluorocarboxylic acids are not suitable for a negative ion MS detection mode.

Because a negative ion MS detection mode is more interesting for the analysis of taurine and its analogs, it is preferable that compatible LC systems with a negative ionization mode be developed. The use of the ELSD is an inexpensive approach for developing the required chromatographic conditions for LC-MS and is more straightforward than MS given that only a few parameters need to be taken into consideration [33]. As a result, the ELSD was used here because MS was not available during the chromatographic development step. Most LC methods can then be directly coupled to MS without any further chromatographic modification.

Porous graphitic carbon not only is a unique hydrophobic stationary phase containing planar $\mathrm{sp}_{2}$ carbon sheaths but also is an electronic-rich adsorbent material. As a result, because of the presence of $\pi$-delocalized electrons on its surface, PGC behavior is often different from that observed in a pure reversed-phase support. Thus, it is possible to observe retention for anionic or cationic organic compounds [34], [35], [36], [37], [38] and [39], and even inorganic anions [34], whereas they are not retained under the same conditions in reversed-phase classical stationary phases. Trifluoroacetic acid is the most widely used electronic competitor [34], [36], [37], [38] and 39], but acetic acid and formic acid are also suitable [38]. Cationic organic compounds could also be analyzed on PGC [36], but it seems that their retention in the PGC stationary phase is more likely due to their hydrophobic moiety. Inorganic cations, such as $\mathrm{Na}^{+}$and $\mathrm{K}^{+}$, could not be retained even using pure water in the mobile phase [38], indicating that on PGC the retention of a cation is less favored than the retention of an anion.

Amino acids are generally rather anionic at high $\mathrm{pH}$ levels. If acetic acid is used as an electronic competitor for their elution on PGC, the mobile phase is acidic and so amino acids are cationic. Moreover, the hydrophobic contribution of the rest of the amino acid is too weak to induce sufficient retention. However, volatile salts, such as ammonia acetate, formate, and 
trifluoroacetate, can be used for $\mathrm{pH}$ control (decreasing or increasing the $\mathrm{pH}$ of the aqueous mobile phase). Separations of several amino acids (e.g., Gly, Thr, Asp, Glu, Asn, Leu, Ile, and Gln) were performed using an ammonium acetate buffer at $\mathrm{pH} 9.3$ adjusted with a twofold ammonia excess as mobile phase [27] on PGC. This kind of mobile phase has been used successfully for total separation of the five proposed sulfur amino acids displayed in Fig. 2 . With the use of a 10-mM ionic strength buffer as mobile phase, this method even allows their total resolution in less than 10 min under isocratic conditions.

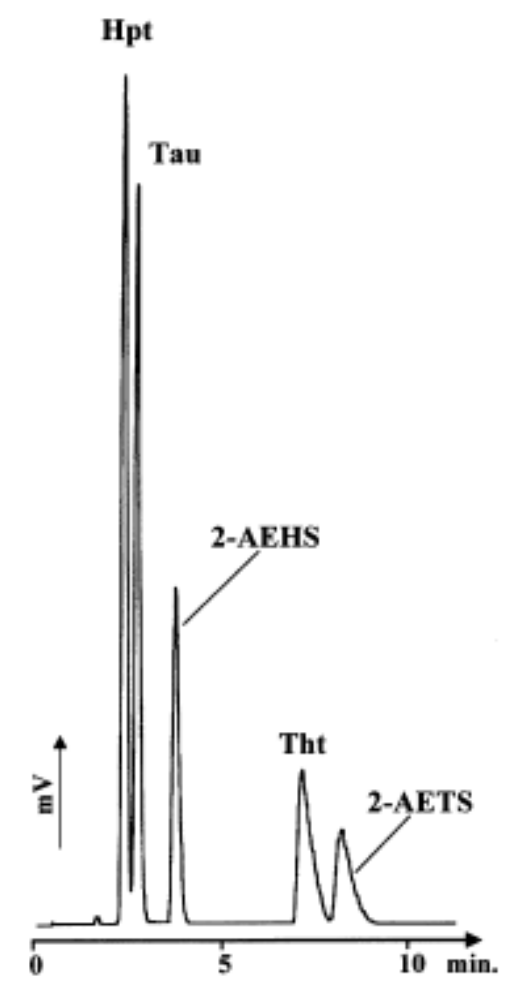

Fig. 2. LC-ELSD analysis of a standard solution of underivatized sulfur amino acids (100 mg/L each) on PGC. Mobile phase: ammonium acetate buffer (ionic strength $10 \mathrm{mM}$ ) at $\mathrm{pH} 9.3$ (adjusted with ammonia). Flow rate, $200 \mu \mathrm{l} / \mathrm{min}$. Injection volume, $10 \mu \mathrm{l}$.

\section{Analysis by LC-MS and LC-MS-MS :}

These optimized LC conditions were then coupled to a negative elecrospray ionization (ESI)MS detection. The alkaline $\mathrm{pH}$ conditions of the mobile phase were well adapted to a sensitive negative detection mode because amino acids under these conditions are negatively charged. Moreover, we found that in negative mode, detection is 10 times more sensitive than in positive mode for thiotaurine, 20 times more sensitive than in positive mode for taurine, and 40 times more sensitive than in positive mode for hypotaurine. As depicted in Fig. 3 , the proposed LC method, developed with the ELSD, was directly and successfully coupled with MS using a 1/10 split at the ion spray entrance. 


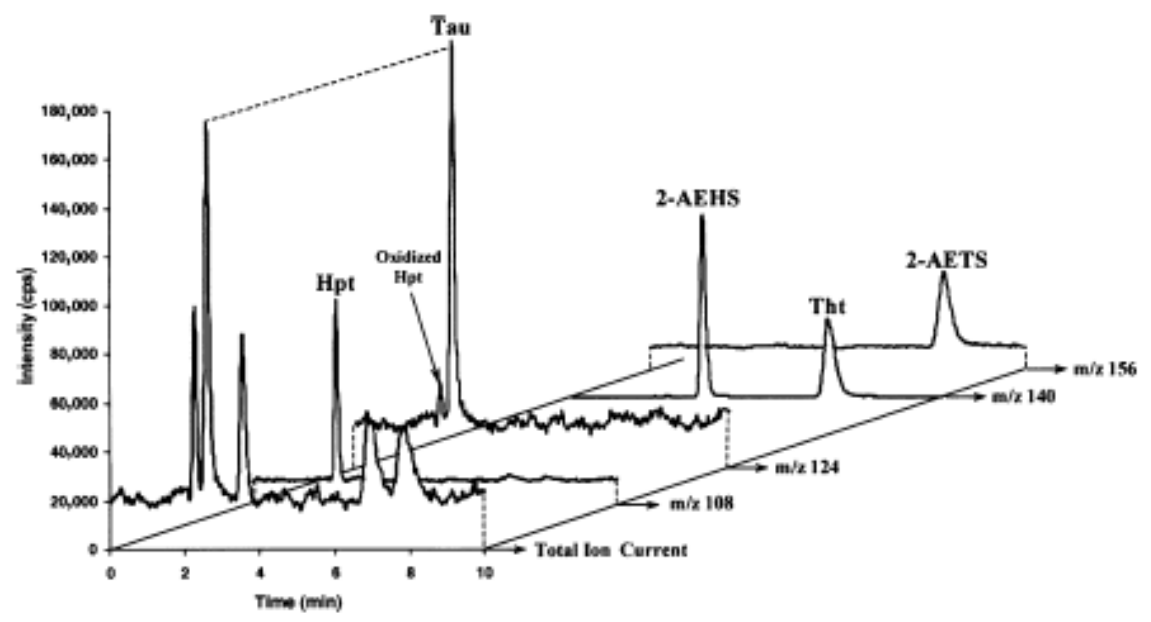

Fig. 3. LC-MS (total ion current and specific extracted ion current) analysis of a standard solution of underivatized sulfur amino acids $(20 \mathrm{mg} / \mathrm{L}$ each) on PGC. Chromatographic conditions: see Fig. 1. Ion spray voltage: $-4.0 \mathrm{kV}$. Split ratio: $1 / 10$. Tht and 2-AEHS have the same nominal mass $(\mathrm{m} / \mathrm{z} 140)$. Note the small amount of oxidized hypotaurine before the taurine peak in the extracted ion current corresponding to $\mathrm{m} / \mathrm{z} 126$.

In MS, coelutions of compounds can be resolved in the event of different $\mathrm{m} / \mathrm{z}$ ratios; however, in the case of Tau and Hpt (which differ in their molecular weights by $16 \mathrm{u}$ ), their chromatographic separation must be maintained. Indeed, in negative ion mode, hypotaurine is partially oxidized in taurine ( $13.5 \%$ of oxidation) in the ion source when the mobile phase is composed of $10 \mathrm{mM}$ of ammonium acetate. This phenomenon is clearly evidenced in Fig. 3 for the ion current corresponding to $m / z$ 124. A small peak of oxidized Hpt can be observed before Tau at $m / z$ 124. This oxidative phenomenon is not entirely surprising, however, because (i) hypotaurine oxidation in taurine is commonly observed through redox reactions [23] and [40] and (ii) ES behaves as an electrolytic cell where redox reactions often occur [41].

Thus, the accurate quantification of Tau is wrong in the case of coelution with Hpt. By reducing the ammonium acetate concentration to $5 \mathrm{mM}$ in the mobile phase, selectivity between Tau and Hpt is increased; however, hypotaurine is nearly totally converted to taurine during the ionization process, and the oxidation rate of hypotaurine in taurine in the ion source is, unfortunately, time dependent and hard to control. Consequently, the MS-MS signal of Hpt (detection for ion transition $108 \rightarrow 64$ ) is always unstable for a given concentration, making a precise and accurate quantification of Hpt problematic. In contrast, with the aqueous mobile phase composed of $10 \mathrm{mM}$ ammonium acetate, the oxidation of $\mathrm{Hpt}$ to Tau remains limited and constant. Consequently, the MS-MS signal of Hpt is stable for a given concentration, enabling a precise and accurate quantification of Hpt. Therefore, this mobile phase composition was chosen and the chromatographic system was further tested in terms of detection limits.

By using a single MS detection mode, the limits of detection (signal-to-noise $(S / N)$ ratio $\geq 3$ ) were $1 \mathrm{mg} / \mathrm{L}$ for Hpt and Tau and $2 \mathrm{mg} / \mathrm{L}$ for Tht. This low sensitivity can be explained by the noisy background of the solvent in the range of $m / z 50-250$, which is a well-known drawback for the detection of low-molecular weight molecules. Tandem MS mode brings detection specificity. Thus, background noise is highly reduced, and limits of detection are lowered to $25 \mu \mathrm{g} / \mathrm{L}$ for Hpt and Tau and to $50 \mu \mathrm{g} / \mathrm{L}$ for Tht, by using tandem MS.

Improvement of MS detection limits using alcohol as "sheath flow" post column addition : These limits of detection for Hpt, Tau, and Tht were rather high for MS-MS detection. One would expect the method to be at least 10 times more sensitive. Sensitive LC-MS methods generally contain a higher amount of organic modifier. Organic modifiers are more volatile 
than water, and they reduce surface tension of the charged microdroplets that are produced during the ES process. Therefore, ion desorption from the droplets is more favored in organicrich mobile phases than in water-rich mobile phases, and sensitivity is increased. The observed low sensitivity is then due to the composition of the LC mobile phase selected (i.e., aqueous solution of ammonium acetate).

To increase sensitivity, some organic modifier must be added in the mobile phase before the ionization process. We chose a post column addition to avoid the perturbation of the chromatographic profile. Post column addition was realized using a sheath flow system (coaxial addition) that is generally used in capillary electrophoresis (CE) [42], [43], [44], [45] and [46]. This kind of system was used previously with LC but was abandoned with the development of pneumatically assisted ES (i.e., ion spray) [47]. Alcohols such as isopropanol [39], [40], [41] and [42], and even longer side chain alcohols such as pentanol [46], are often used as makeup in CE.

Alcohols were tested from methanol to pentanol as additional makeup as well as the influence

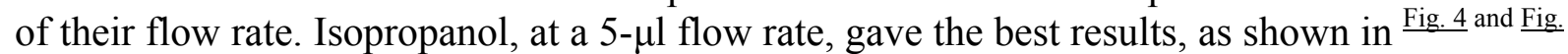
$\underline{5}$. Limits of detection were improved by approximately a factor of 5 for Hpt and Tau to reach $5 \mu \mathrm{g} / \mathrm{L}$, and the limit of detection was $10 \mu \mathrm{g} / \mathrm{L}$ for Tht.

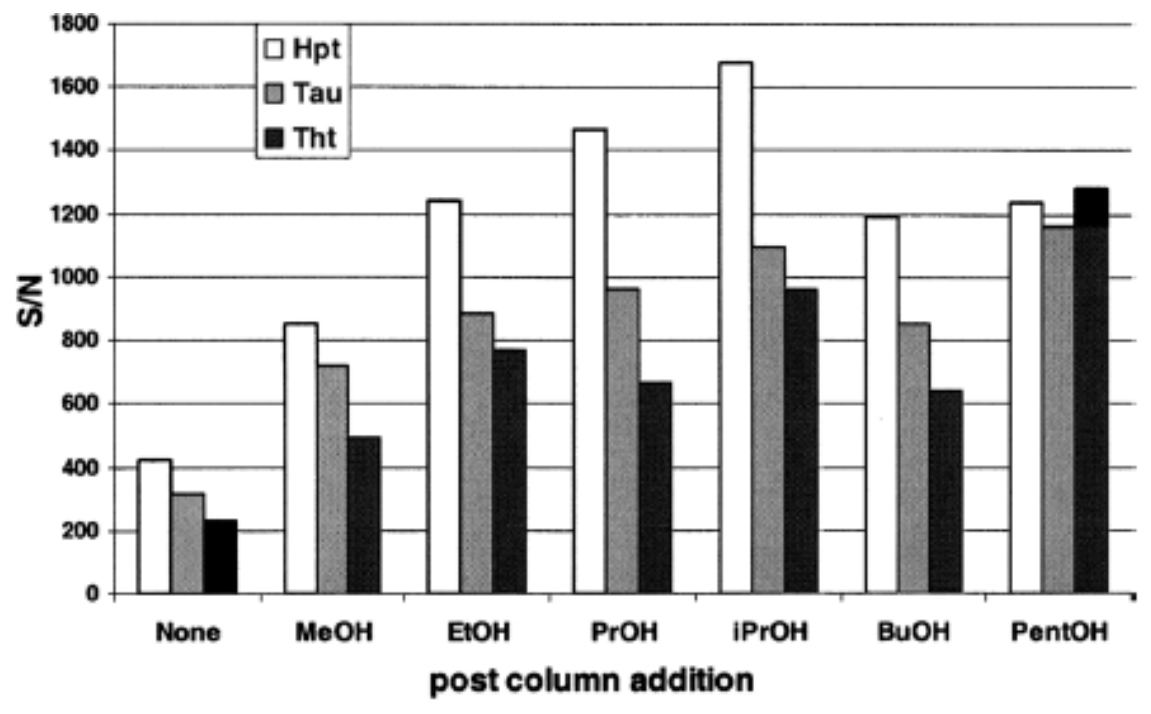

Fig. 4. Influence of the nature of the alcohol used as post column addition on the $S / N$ ratio observed for the three sulfur amino acids of interest $(10 \mathrm{mg} / \mathrm{L})$ during their LC-MS-MS analysis. Chromatographic conditions: see Fig. 3. Flow rate of the sheath flow liquid: $10 \mu \mathrm{l} / \mathrm{min}$. MeOH, methanol; EtOH, ethanol; PrOH, $n$-propanol; iPrOH, isopropanol; $\mathrm{BuOH}$, butanol; and PentOH, pentanol. Given that the split ratio of the mobile phase before introduction in the source is $1 / 10$, the nebulized mobile phase flow rate is $20 \mu \mathrm{l} / \mathrm{min}$. 


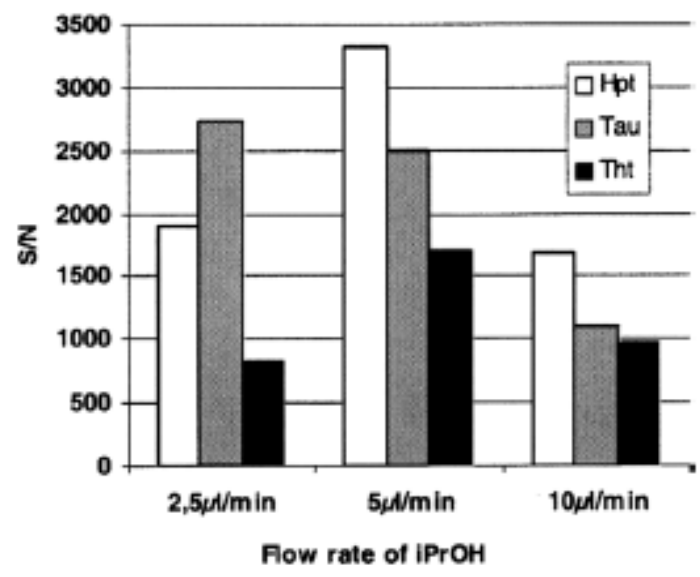

Fig. 5. Influence of flow rate of the post column addition (isopropanol) on the $S / N$ ratio observed for the three sulfur amino acids of interest $(10 \mathrm{mg} / \mathrm{L})$ during their LC-MS-MS analysis. Chromatographic conditions: see Fig. 3.

Assays of taurine, hypotaurine, and thiotaurine in the tissues of some marine symbiotic invertebrates

An internal standard method was used to measure the sulfur amino acid amounts in several invertebrate samples, and 2-AEHS was employed as the internal standard. Indeed, by monitoring the specific 2-AEHS ion transition $(140 \rightarrow 97)$, as well as the specific 2-AETS ion transition $(156 \rightarrow 80)$, no traces of these two substances were found in the biological samples analyzed. Moreover, it appears that under the chromatographic conditions used, the elution of 2-AEHS (Fig. 2) between the Hpt-Tau pair and Tht is more appropriate for an internal standard than is 2-AETS as the last eluted compound. We should point out here that 2-AEHS might not be the most appropriate internal standard when compared with stable isotopelabeled analogs for MS detection, but the latter are not commercially available and their chemical synthesis is both time-consuming and expensive. Assays of hypotaurine, taurine, and thiotaurine have been carried out on several samples of invertebrates. Because of the high amount of these sulfur-containing amino acids in the tissues, samples were diluted in the mobile phase by a factor of 10 before injection. Consequently, matrix effects (i.e., ion suppression due to ionization competition) are suppressed. Calibration curves were performed between 0.75 and $100 \mathrm{mg} / \mathrm{L}$ (using seven standard calibration levels in triplicate: $0.75,1,5$, $10,25,50$, and $100 \mathrm{mg} / \mathrm{L}$ ). This concentration range was selected according to the sulfur amino acid content of the studied samples. Coefficients of correlation were found to be greater than 0.992 for Hpt, and greater than 0.998 for Tau and Tht, using a linear fit model.

Fig. 6 depicts an LC-MS-MS analysis of an extract from gills of a Calyptogena species (from Barbados). The extracted ion chromatograms (XIC) allow the specific identification and quantification of taurine (ion transition $124 \rightarrow 80$ ) and thiotaurine (ion transition $140 \rightarrow 96$ ). Hypotaurine (ion transition $108 \rightarrow 64$ ), in contrast, cannot be detected in this sample $(<5 \mu \mathrm{g} / \mathrm{L})$, corresponding roughly to $1 \mathrm{nmol} / \mathrm{g}$ dry weight of tissue. The concentrations of taurine and thiotaurine are 11 and $16 \mu \mathrm{mol} / \mathrm{g}$ dry weight of tissue, respectively, in this analyzed sample. 


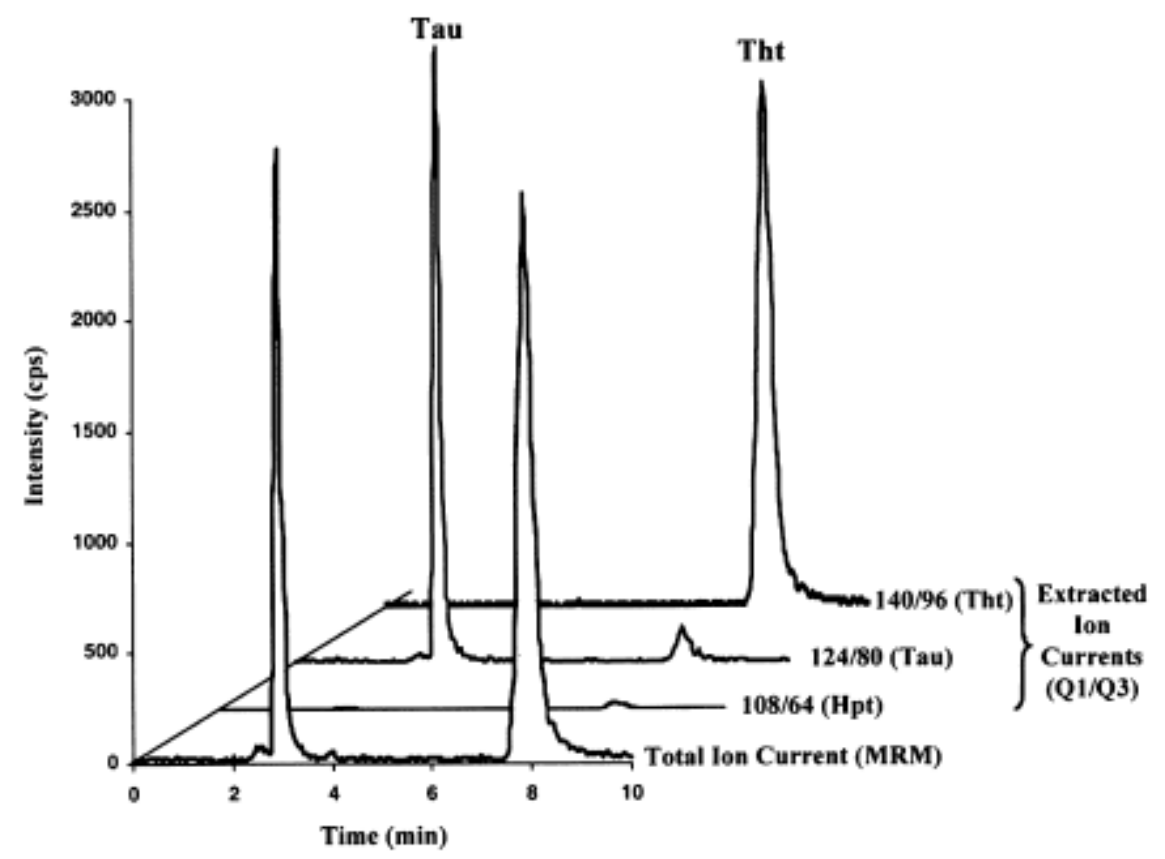

Fig. 6. LC-MS-MS (total ion current and specific extracted ion current) analysis of an extract of gills from a vesicomyid clam (from Barbados) on PGC. Chromatographic conditions: see Fig. 3. Total ion current is obtained from the multiple reaction monitoring of the ionic currents corresponding to the specific ion transition of $\mathrm{Hpt}$ (deprotonated molecular ion at $\mathrm{m} / \mathrm{z} 108$ gives fragment ion at $\mathrm{m} / \mathrm{z} 64$ ), Tau (deprotonated molecular ion at $\mathrm{m} / \mathrm{z}$ 124 gives fragment ion at $\mathrm{m} / \mathrm{z} 80$ ), and Tht (deprotonated molecular ion at $\mathrm{m} / \mathrm{z} 140$ gives fragment ion at $\mathrm{m} / \mathrm{z}$ 96). No internal standard was used for this displayed analysis.

The quantification results for two bivalves (B. thermophilus andC. magnifica from Galapagos) and a tubeworm ( $R$. pachyptila) are shown in Table 2. This is the first confirmation using MS of the presence of thiotaurine in the tissues of these symbiotic invertebrates. Although reported by several studies and different groups, the compound so far has been only tentatively determined by indirect methods [3], [4], [6], [7], [9], [10] and [11]. Discussion of the signification of the differences found among species, individuals, or tissues is outside the scope of the current study. Nevertheless, apart from having unequivocally established the occurrence of thiotaurine in these organisms, this study confirms some previous results, for example, the absence of hypotaurine in the gills of a vesicomyid clam from Barbados mentioned by Alberic and Boulègue [4] (see ion transition 108 $\rightarrow 64$ in Fig. 6) and the contrasting occurrence of thiotaurine and hypotaurine in the trophosome and gills of $R$. pachyptila [3].

\begin{tabular}{|c|c|c|c|c|}
\hline \multirow[t]{2}{*}{ Species } & \multicolumn{4}{|c|}{ Concentration in tissues ( $\mu \mathrm{mol} / \mathrm{g}$ dry weight) } \\
\hline & Tissues & $\mathrm{Hpt}$ & Tau & Tht \\
\hline \multirow[t]{2}{*}{ Bathymodiolus thermophüus (Galapagos) } & Gills & 50.4 & 44.8 & 22.7 \\
\hline & Mantle & 2.8 & 25.8 & 1.7 \\
\hline Calyptogena magnifica (Galapagos) & Gills & 94.2 & 77.8 & 73.8 \\
\hline \multirow[t]{2}{*}{ Riffia pachyptila (East Pacific Rise, $13^{\circ} \mathrm{N}$ ) } & Trophosome & 2.5 & 20.5 & $>200^{a}$ \\
\hline & Gills & $>200^{a}$ & 81.6 & 4.8 \\
\hline
\end{tabular}

Table 2. : Quantification ( $\mu \mathrm{mol} / \mathrm{g}$ of dry weight) of hypotaurine, taurine, and thiotaurine in some deep sea invertebrates living in the vicinity of hydrothermal vents 


\begin{tabular}{|l|l|l|l|l|}
\hline & \multicolumn{4}{|l|}{ Concentration in tissues ( $\mu \mathrm{mol} / \mathrm{g}$ dry weight) } \\
\hline Species & Tissues & $\mathrm{Hpt}$ & $\mathrm{Tau}$ & $\mathrm{Tht}$ \\
\hline Bathymodiolus thermophilus (Galapagos) & Gills & 50.4 & 44.8 & 22.7 \\
\hline & Mantle & 2.8 & 25.8 & 1.7 \\
\hline Calyptogena magnifica $($ Galapagos) & Gills & 94.2 & 77.8 & 73.8 \\
\hline Riftia pachyptila (East Pacific Rise, $\left.13^{\circ} \mathrm{N}\right)$ & Trophosome & 2.5 & 20.5 & $>200^{\mathrm{a}}$ \\
\hline & Gills & $>200^{\mathrm{a}}$ & 81.6 & 4.8 \\
\hline
\end{tabular}

Note. Each sample was analyzed twice, and the difference between the two determinations did not exceed $9 \%$ except for $\mathrm{Hpt}$ in the gills of $B$. thermophilus $(14 \%)$. ${ }^{\mathrm{a}}$ Out of range; must be diluted before a new determination is made (otherwise, other compounds will be too diluted).

\section{Conclusion}

The goal of this study was to develop a reliable analytical method to characterize and quantify unusual sulfur amino compounds, especially thiotaurine, found in symbiotic deep marine invertebrates. Coupling LC with tandem MS proves to be a reliable procedure for the identification and quantification of metabolites in biological samples given that MS-MS detection is a highly sensitive and specific detection mode, whereas LC provides selectivity between the remaining isobars or isomers contained in the matrices. Sulfur amino acids are extracted from tissues (no derivatization step is needed, thereby reducing artifacts), filtered, and diluted before injection. As a result, sample preparation is reduced in comparison with other analytical procedures, and analysis time is only $10 \mathrm{~min}$. The current three-dimensional procedure, where parent ion is the first dimension, specific fragment ion is the second dimension, and retention time is the third dimension, is much more reliable for biological sample analysis than are most of the other procedures.

By using the above-described LC-MS-MS method in this study, thiotaurine, which currently has been detected only in deep sea symbiotic organisms, was unambiguously shown to be present in these biological matrices, and its concentration was determined. Taurine and hypotaurine, which are commonly occurring metabolites, were also easily and rapidly assayed.

It should also be pointed out that the mass spectrometer used in this study belongs to an old generation. One can now expect more sensitive results with a new-generation spectrometer, or even a turbo ion spray source, rather than with the classical ion spray source. Indeed, the turbo ion spray is a thermally assisted ion source. Consequently, it is higher flow rate tolerant [48], [49] and [50]; thus, splitting the mobile phase is no longer necessary, and sensitivity is improved [50].

Finally, the interest in taurine analogs such as thiotaurine is not restricted to marine sciences, and an LC-MS method focusing on these compounds may well find applications in other fields such as the neurosciences 117$]$ and [51]

To this point, the proposed LC-MS-MS methods optimized for amino acid analysis use acidic LC conditions more suitable for the positive ion mode MS detection [30] and [31]. Unfortunately, several amino acids (mainly phosphorus- and sulfur-containing amino acids) have a significantly low response in this positive ion mode [31]. Moreover, other compounds involved in inherited disorders, such as orotic acid and orotidine, can be detected only in 
negative ionization mode [31]. Therefore, appropriate LC conditions using alkaline mobile phases, compatible with MS detection of amino acids in a negative ionization mode, must be developed. The methodology proposed in this article constitutes a promising approach for analysis of underivatized amino acids in negative ion mode MS detection.

\section{Acknowledgments}

We thank the scientific teams and the crew of the joint French-U.S. hydrothermal vent cruise Hydronaut for their assistance in collecting material. This study was partially supported by a financial Grant (02/CNES/4800000093) from the Centre National d'Etudes Spatiales (CNES).

\section{References}

[1] H.W. Janash and M.J. Mottl, Geomicrobiology of deep-sea hydrothermal vents, Science 229 (1985), pp. 717-725.

[2] H.W. Janash and C.O. Wirsen, Chemosynthetic primary production at East Pacific sea floor spreading center, Bioscience 29 (1979), pp. 592-598.

[3] P. Albéric, Présence de quantités importantes de thiotaurine et d'hypotaurine dans les tissus de Riftia pachyptila (Pogonophore, Vestimentifère), C. R. Acad. Sci. Paris Série III 302 (1986), pp. 503-508.

[4] P. Alberic and J. Boulègue, Unusual amino compounds in the tissues of Calyptogena phaseoliformis (Japan trench): possible link to symbiosis, Prog. Oceanogr. 24 (1990), pp. 89101.

[5] P. Albéric, A. Fiala-Médioni and J. Boulègue, Acide diaminopimélique libre des bivalves symbiotiques, C. R. Acad. Sci. Paris, Sciences de la vie 318 (1995), pp. 1053-1057.

[6] A.M. Pruski, A. Fiala-Medioni, C.R. Fisher and J.-C. Colomines, Composition of free amino acids and related compounds in invertebrates with symbiotic bacteria at hydrocarbon seeps in the Gulf of Mexico, Mar. Biol. 136 (2000), pp. 411-420.

[7] A.M. Pruski, A. Fiala-Medioni, R. Prodon and J.-C. Colomines, Thiotaurine is a biomarker of sulfide-based symbiosis in deep-sea bivalves, Limnol. Oceanogr. 45 (2000), pp. 1860-1867.

[8] A.M. Pruski, R. De Wit and A. Fiala-Médioni, Carrier of reduced sulfur is a possible role for thiotaurine in symbiotic species from hydrothermal vents thiotrophic symbionts, Hydrobiologia 461 (2001), pp. 9-13.

[9] V. Pranal, A. Fiala-Medioni and J.-C. Colomines, Amino acids and related compound composition in two symbiotic mytilid species from hydrothermal vents, Mar. Ecol. Prog. Ser. 119 (1995), pp. 155-166.

[10] M. Yin, H.R. Palmer, A.L. Fyfe-Johnson, J.J. Bedford, R.A.J. Smith and P.H. Yancey, Hypotaurine, $\mathrm{N}$-methyltaurine, taurine, and glycine betaine as dominant osmolytes of vestimentiferan tubeworms from hydrothermal vents and cold seeps, Phys. Biochem. Zool. 73 (2000), pp. 629-637.

[11] J.C. Fiess, H.A. Hudson, J.R. Hom, C. Kato and P.H. Yancey, Phosphodiester amine, taurine and derivatives, and other osmolytes in vesicomyid bivalves: correlations with depth and symbiont metabolism, Cahiers Biol. Mar. 43 (2002), pp. 337-340.

[12] P.H. Yancey, W.R. Blake and J. Conley, Unusual organic osmolytes in deap-sea animals: adaptations to hydrostatic pressure and other perturbants, Comp. Biochem. Physiol. A 133 (2002), pp. 667-676.

[13] L.L. Hirshberger, J. De La Rosa and M.H. Stipanuk, Determination of cysteinesulfinate, hypotaurine, and taurine in physiological samples by reversed-phase high-performance liquid chromatography, J. Chromatogr. 343 (1985), pp. 303-313. 
[14] T.J. Amiss, K.L. Tyczkowska and D.P. Aucoin, Analysis of taurine in feline plasma and whole blood by liquid chromatography with fluorimetric detection and confirmation by thermospray mass spectrometry, J. Chromatogr. 526 (1990), pp. 375-382.

[15] T. Sakai and T. Nagasawa, Simple, rapid, and sensitive determination of plasma taurine by high-performance liquid chromatography using pre-column derivative formation with fluorescamine, J. Chromatogr. Biomed. Appl. 576 (1992), pp. 515-557.

[16] V. Stocchi, F. Palma, G. Piccoli, B. Biaggiarelli, L. Cucchiaraini and M. Magnani, HPLC analysis of taurine in human plasma sample using the DABS-Cl reagent with sensitivity at picomole level, J. Liq. Chromatogr. Rel. Technol. 17 (1994), pp. 347-357.

[17] H. Liu, M. Clara Sañuda-Peña, J. Dale Harvey-White, S. Kalra and S.A. Cohen, Determination of submicromolar concentration of neurotransmitter amino acids by fluorescence detection using a modification of the 6-aminoquinolyl- $N$-hydroysuccinimidyl carbamate method for amino acid analysis, J. Chromatogr. A 828 (1998), pp. 383-395.

[18] C.J. Waterfield, Determination of taurine in biological samples and isolated hepatocytes by high-performance liquid chromatography with fluorimetric detection, J. Chromatogr. B 657 (1994), pp. 37-45.

[19] I.M.P.L.V.O. Feireira, M.V. Nunes, E. Mendes, R. Remiao and M.A. Feireira, Development of an HPLC-UV method for the determination of taurine in infant formulae and breast milk, J. Liq. Chromatogr. Rel. Technol. 20 (1997), pp. 1269-1278.

[20] T. Togawa, A. Oshawa, K. Kawanabe and S. Tanabe, Simultaneous determination of cystein sulfinic acid and hypotaurine in rat tissues by column switching high-performance liquid chromatography with electrochemical detection, J. Chromatogr. B 704 (1997), pp. 8388 .

[21] F. Qu, Z.-H. Qi, K.-N. Liu and S.-F. Mou, Ion chromatographic determination of taurine in medicine, nutrient capsule, and human urine with electrochemical detection, $J$. Chromatogr. B 730 (1999), pp. 161-166.

[22] S.J. Lillard, D.T. Chiu, R.H. Scheller, R.H. Zare, S.E. Rodriguez-Cruz, R. Williams, O. Orwar, M. Sandberg and J.A. Lundqvist, Separation and characterization of amines from individual atrial gland of Aplisia californica, Anal. Chem. 70 (1998), pp. 3517-3524.

[23] S. Dupré, A. Spirito, K. Sugahara and H. Kodama, Hypotaurine oxidation: an HPLCmass approach, Adv. Exp. Med. Biol. 442 (1998), pp. 3-8.

[24] P. Chaimbault, K. Petritis, C. Elfakir and M. Dreux, Determination of 20 underivatized proteinic amino acids by ion-pairing chromatography and pneumatically assisted electrospray, J. Chromatogr. A 855 (1999), pp. 191-202.

[25] P. Chaimbault, K. Petritis, C. Elfakir and M. Dreux, Ion-pair chromatography on a porous graphitic carbon stationary phase for the analysis of twenty underivatized protein amino acids, J. Chromatogr. A 870 (2000), pp. 245-254.

[26] K. Petritis, P. Chaimbault, C. Elfakir and M. Dreux, Parameter optimisation for the analysis of underivatized protein amino acids by liquid chromatography and ion spray mass spectrometry, J. Chromatogr. A 896 (2000), pp. 253-263.

[27] P. Chaimbault, Analyse d'acides aminés non derivés par chromatographie en phase liquide avec le détecteur évaporatif à diffusion de la lumière et couplage avec la spectrométrie de masse, Ph.D. thesis, Université d'Orléans, France, 2000.

[28] K. Petritis, Nouvelles méthodes de séparation chirales et non chirales des acides aminés non dérivés par chromatographie en phase liquide et couplage à différents modes de détection: dosage dans les matrices complexes, Ph.D. thesis, Université d'Orléans, France, 2002.

[29] J. Qu, W. Chen, G. Luo, Y. Wang, S. Xiao, Z. Ling and G. Chen, Rapid determination of underivatized pyroglutamic acid glutamic acid, glutamine, and relevant amino acids in fermentation media by LC-MS-MS, Analyst 127 (2002), pp. 66-69. 
[30] J. Qu, Y. Wang, G. Luo, Z. Wu and C. Yang, Validated quantification of underivatized amino acids in human blood samples by volatile ion-pair reversed-phase liquid chromatography coupled to isotope dilution tandem mass spectrometry, Anal. Chem. 74 (2002), pp. 2034-2040.

[31] M. Piraud, C. Vianey-Saban, K. Petritis, C. Elfakir, J.-P. Steghens, A. Morla and D. Bouchu, ESI-MS/MS analysis of underivatised amino acids: a new tool for the diagnosis of inherited disorders of amino acid metabolism-Fragmentation study of 79 molecules of biological interest in positive and negative ionization mode, Rapid Commun. Mass Spectr. 17 (2003), pp. 1-15.

[32] D. Cavallini, C. De Marco and B. Mondovi, Chromatographic evidence on the occurrence of thiotaurine in the urine of rats fed with cystine, J. Biol. Chem. 234 (1959), pp. 854-857.

[33] M. Dreux, M. Lafosse and L. Morin-Allory, The evaporative light scattering detector: a universal instrument for non-volatile solutes in LC and SFC, LCGC Int. 9 (1996), pp. 148156.

[34] C.K. Lim, Electronic interaction chromatography on porous graphitic carbon: separation of [ $\left.{ }^{99 \mathrm{~m}} \mathrm{Tc}\right]$ pertechnate and perrhenate anions, Biomed. Chromatogr. 3 (1989), pp. 92-93.

[35] H.C. Ehrsson, I.B. Wallin, A.S. Andersson and P.O. Edlund, Cisplatin, transplatin, and their hydrated complexes: separation and identification using porous graphitic carbon and electrospray ionization mass spectrometry, Anal. Chem. 67 (1995), pp. 3608-3611.

[36] G. Gu and C.K. Lim, Separation of anionic and cationic compounds of biomedical interest by HPLC on porous graphite carbon, J. Chromatogr. 515 (1990), pp. 183-192. $\underline{\text { Abstract }}$

[37] C. Elfakir and M. Dreux, Simultaneous analysis of intact and desulfated glucosinolates with a porous graphitised carbon column, J. Chromatogr. A 727 (1996), pp. 71-82.

[38] C. Elfakir, P. Chaimbault and M. Dreux, Determination of inorganic anions on porous graphitic carbon using evaporative light scattering detection: use of carboxylic acids as electronic competitors, J. Chromatogr. A 829 (1998), pp. 193-199.

[39] M. Josefsson, B. Carlsson and B. Norlander, Chiral ion-pair chromatographic separation of two dihydropyridines with camphorsulfonic acids on porous graphitic carbon, $J$. Chromatogr. A 684 (1994), pp. 23-27.

[40] B.S. Martincigh, C. Mundoma and R.H. Simoyi, Antioxidant chemistry: hypotaurinetaurine oxidation by chlorite, J. Phys. Chem. A 102 (1998), pp. 9838-9846.

[41] R.B. Cole, Electrospray Ionization Mass Spectrometry: Fundamentals, Instrumentation, and Applications, Wiley-Interscience, New York (1997).

[42] J. Cai and J. Hennion, Capillary electrophoresis-mass spectrometry, J. Chromatogr. A 703 (1995), pp. 667-692.

[43] M.W. Nielen, Industrial application of capillary zone electrophoresis-mass spectrometry, J. Chromatogr. A 712 (1995), pp. 269-284.

[44] T.E. Wheat, K.A. Lilley and J.F. Banks, Capillary electrophoresis with electrospray mass spectrometry detection for low-molecular-mass compounds, J. Chromatogr. A 781 (1997), pp. 99-105.

[45] C. Siethoff, N. Nigge and M. Linscheid, Characterization of a capillary zone electrophoresis/electrospray-mass spectrometry interface, Anal. Chem. 70 (1998), pp. 13571361.

[46] J.-P. Mercier, P. Chaimbault, P. Morin, M. Dreux and A. Tambuté, Identification of phosphonic acids by capillary electrophoresis-ion spray mass spectrometry, J. Chromatogr. A 825 (1998), pp. 71-80.

[47] A.P. Bruins, Mechanistic aspects of electrospray ionization, J. Chromatogr. A 794 (1998), pp. 345-357. 
[48] G. Hopfgartner, K. Bean, J. Henion and R. Henry, Ion spray mass spectrometric detection for liquid chromatography: a concentration- or a mass flow-sensitive device, $J$. Chromatogr. 647 (1993), pp. 51-61.

[49] W.M.A. Niessen, Advances in instrumentation in liquid chromatography-mass spectrometry and related liquid-introduction techniques, J. Chromatogr. A 794 (1998), pp. 407-435.

[50] S. Tamogami and O. Komada, Quantification of amino acid conjugates of cisjasmonicacid in rice leaves by high-performance liquid chromatography-turbo ion spray tandem mass spectrometry, J. Chromatogr. A 822 (1998), pp. 310-315.

[51] M. Costa, L. Vesci, M. Fontana, S.P. Solinas, S. Dupre and D. Cavallini, Displacement of $[3 \mathrm{H}] \mathrm{GABA}$ binding to bovine brain receptors by sulfur-containing analogues, Neurochem. Intl. 17 (1990), pp. 547-551. 